\title{
Study of Thermal Degradation of PLGA, PLGA Nanospheres and PLGA/Maghemite Superparamagnetic Nanospheres
}

\author{
Marcela Fernandes Silva ${ }^{a *}$, Ana Adelina Winkler Hechenleitner ${ }^{a}$, Juan Manuel Irache ${ }^{b}$, \\ Adilson Jesus Aparecido de Oliveira ${ }^{c}$, Edgardo Alfonso Gómez Pineda ${ }^{a}$ \\ ${ }^{a}$ Universidade Estadual de Maringá - UEM, Av. Colombo, 5790, CEP 87020-900, Maringá, PR, Brazil \\ ${ }^{b}$ Universidad de Navarra, Campus Universitario, 31009, Pamplona, Navarra, Spain \\ ${ }^{c}$ Universidade Federal de São Carlos - UFSCar, Rodovia Washington Luís, Km 235, \\ CEP 13565-905, São Carlos, SP, Brazil
}

Received: September 21, 2015; Revised: September 21, 2015

\begin{abstract}
Poly(glycolide-co-lactide) (PLGA) nanospheres containing magnetic materials have been extensively studied because of its biomedical applications. Therefore, it is very important to know thermal properties of these materials in addition to other physical properties. Thermal degradation activation energy $\left(\mathrm{E}_{\alpha}\right)$ of PLGA nanospheres with maghemite entrapment (PLGA-Mag), PLGA nanospheres (hollow spheres) (PLGA-H) obtained by an emulsion method and unprocessed PLGA (PLGA-R) were calculated by isoconversional Vyazovkin method based on data of TG analysis in order to evaluate modifications in thermal behavior caused by nanospheres obtainment process or by maghemite entrapment. Both hydrodynamic diameter in the range of $200-250 \mathrm{~nm}$ and polydispersity index lower than 0.3 are considered satisfactory. Thermal degradation of PLGA-R begins at higher temperatures than those of PLGA-H and PLGA-Mag, but processed samples presented increase in thermal stability, which was greater before processing by emulsion and in the presence of the magnetic materials. PLGA-Mag presents superparamagnetic behavior at room temperature.
\end{abstract}

Keywords: PLGA, iron oxide, nanospheres, thermal degradation, activation energy

\section{Introduction}

Magnetic nanoparticles like iron oxides are of great interest for researchers from a wide range of disciplines, including magnetic fluids, catalysis, biotechnology/biomedicine, magnetic resonance imaging, data storage, and environmental remediation ${ }^{1-4}$. While a number of suitable methods have been developed for the synthesis of magnetic nanoparticles of various different compositions, successful application of such magnetic nanoparticles in the areas listed above is highly dependent on the stability of the particles under a range of different conditions. In most of the envisaged applications, the particles perform best when the size of the nanoparticles is below a critical value, which is dependent on the material but is typically around $10-20 \mathrm{~nm}$. However, an unavoidable problem associated with particles in this size range is their intrinsic instability over longer periods of time. Such small particles tend to form agglomerates to reduce the energy associated with the high surface area to volume ratio of the nanosized particles ${ }^{5}$. Moreover, naked metallic nanoparticles are chemically highly active, and are easily oxidized in air, resulting generally in loss of magnetism and dispersibility. For many applications it is thus crucial to develop protection strategies to chemically stabilize the naked magnetic nanoparticles against degradation during or after the synthesis. These strategies comprise grafting or coating with organic species, including surfactants or

*e-mail: celafs@gmail.com polymers, or coating with an inorganic layer, such as silica or carbon. It is noteworthy that in many cases the protecting shells not only stabilize the nanoparticles, but can also be used for further functionalization, for instance with other nanoparticles or various ligands, depending on the desired application ${ }^{6}$. For biomedical applications, properties like biodegradability and biocompatibility are required ${ }^{7}$.

Some polymers are used for the coating of magnetic nanoparticles, like PEG, PVA, PVP, PLGA, dextran, chitosan among others. PLGA has been extensively studied because is a FDA approved material ${ }^{8-10}$. PLGA containing magnetic materials have been extensively studied due to its main biomedical applications such as drug-delivery, magnetic resonance imaging and magnetic hyperthermia. Because of their magnetic properties, such materials may be driven to specific sites, such as a tumor, carried by the action of a magnetic field. Due to the magnetic properties, these materials may be submitted to the action of certain types/intensities of magnetic fields, causing the temperature to rise, which, in turn, has the ability to destroy cancer cells, whose susceptibility to heat is higher than that of normal cells ${ }^{11-13}$. Cancer is a multifaceted and genomically complex disease and rapidly emerging experimental evidence has started to shed light on wide ranging factors which underlie cancer development and progression. Confluence of information suggested various nanotechnological approaches to enhance delivery of anticancer agents to the tumor site ${ }^{14-17}$. 
Still, because of the degradation ability of PLGA, these materials can be drug carriers, which will, in turn, be released in these specific locations, thus decreasing the side effects caused by medicines to normal cells ${ }^{11-13}$.

However, besides knowing the properties previously mentioned, it is important to know the behavior of the material that is being processed, to avoid future problems as stability loss or degradation. In general, most in vitro degradation experiments are conducted at the physiologically relevant temperature of $37^{\circ} \mathrm{C}$. However, the degradation of most commonly used PLGA materials is relatively slow at $37^{\circ} \mathrm{C}$, and studies may take several weeks or even years to be completed. Consequently, there is a need to establish techniques to decrease the duration of these studies while ensuring that the results remain relevant and valid ${ }^{18}$.

Thermal analytical methods have been widely used in the study of the relationship between a material and its processing conditions. These methods can be applied to the study of any physical or chemical (such as thermal degradation) process. Thermal stabilities of polymers are different and the characteristic temperatures and the extent and kinetics of decomposition given by thermal analysis are rapid means of obtaining their identification and characterization ${ }^{19}$.

Also, the thermal analysis of polymer materials is a suitable method of providing complementary and supplementary characterization information that can be used to select them for certain end-use applications, predict product performance, and improve product quality. The technique can analyze materials that exhibit either mass loss or gain due to decomposition, oxidation, or even loss of volatiles (such as moisture). It is valuable in the measurement of thermal stabilities, oxidative stabilities, decomposition kinetics, estimation of product lifetimes, effects of reactive atmospheres on materials, moisture and volatiles content, and so on ${ }^{19}$.

As a general observation, it might be said that the thermal and magnetic properties together with biocompatibility or biodegradability properties might allow for their use in several of the proposed biomedical applications, thus avoiding the problem of unexpected and unpredictable physical changes that can happen when they are processed during their production (such as thermal stability changes due to PLGA solubilization/lyophilization or iron oxide interaction), when applied to the human body, or when they are stored for later use. Several studies have demonstrated the importance of thermal characterization of bulk PLGA and materials based on such polymer, for better understanding of its stabilities, degradation, among other properties ${ }^{20-22}$.

In this work, hollow PLGA nanospheres and PLGA magnetic nanospheres (with maghemite entrapment) were characterized. The isoconversional method of Vyazovkin ${ }^{23}$ was employed for the determination of activation energy variation with respect to the degree of degradation. To our knowledge, there are no previous results in the literature about studying the kinetics pyrolysis of PLGA and derivatives.

\section{Experimental}

\subsection{Material}

Ferric nitrate $\left(\mathrm{Fe}\left(\mathrm{NO}_{3}\right)_{3} \cdot 9 \mathrm{H}_{2} \mathrm{O}\right)$ (Vetec, Brazil), poly(vinyl alcohol) (PVA; MW 146,000-180,000 88-89\% hydrolyzed) (Aldrich,USA), Pluronic F-68 (Sigma-Aldrich, USA), Poly-lactic-co-glycolic acid with a monomer ratio of 50:50 (Resomer ${ }^{\circledR}$ RG 502, Boehringer Ingelheim, Germany) (PLGA-R), ethyl acetate (99\% - Panreac, Spain), dichloromethane (99\% - Merck, Germany) sodium citrate tribasic dehydrate (ACS 99\% - Sigma Aldrich, USA), sucrose (Fragon, Spain). All organic solvents used were of analytical grade, without previous purificaton.

\subsection{Methods}

\subsubsection{Synthesis of maghemite nanoparticles (Mag)}

The maghemite nanoparticles (Mag) were synthetized by a modified sol-gel method ${ }^{3}$. Aqueous diluted PVA $(10 \% \mathrm{w} / \mathrm{v})$ and saturated ferric nitrate solutions were separately prepared and then mixed at specific metallic ion/monomer unit ratios. The solutions were maintained at room temperature under stirring for $2 \mathrm{~h}$ and then heated under vigorous stirring until total water evaporation. The temperature was maintained at $150^{\circ} \mathrm{C}$ for thermal degradation of the polymer. The nanostructured material was obtained after calcination of the material under air atmosphere at $400{ }^{\circ} \mathrm{C}$ for $4 \mathrm{~h}$ for elimination of residual organic materials from PVA.

\subsubsection{Preparation of maghemite loaded-PLGA nanospheres (PLGA-Mag) and PLGA hollow nanospheres (PLGA-H)}

The preparation of the PLGA magnetic nanospheres (with maghemite entrapment) (PLGA-Mag) or PLGA nanospheres (hollow spheres) (PLGA-H) was performed by using single emulsion method ${ }^{4}$. The maghemite nanoparticles were dispersed in organic solvent by sonication for $1 \mathrm{~min}$. Then, the dichloromethane PLGA solution was added and this organic mixture was emulsified by sonication in $3 \mathrm{~mL}$ of aqueous PVA solution in an ice bath. After emulsion, the organic solvent was evaporated under magnetic stirring. After solvent removal, the emulsion was centrifuged at $1000 \mathrm{rpm}$ for $20 \mathrm{~min}$ at $4{ }^{\circ} \mathrm{C}$ to precipitate the magnetic nanoparticles not entrapped. In these conditions free maghemite could be separated from the composite nanoparticles. Then, the formed composite nanoparticles were separated by ultracentrifugation at $17000 \mathrm{rpm}$ for $10 \mathrm{~min}$ and freeze-dried. Sucrose 5\% (w/v) was added as a cryoprotectant to preserve the particle properties during freezing step. These tests were performed in triplicate.

The mean hydrodynamic diameter and the zeta potential of nanoparticles were determined by photon correlation spectroscopy (PCS) and electrophoretic laser Doppler anemometry, respectively, using a Zetamaster analyzer system (Malvern Instruments, UK). For this purpose, samples were diluted with deionized water and measured at $25^{\circ} \mathrm{C}$ with a scattering angle of $90^{\circ}$. The magnetic measurements (magnetization versus applied magnetic field curves, $\mathrm{M}-\mathrm{H}$ and magnetization versus temperature, $\mathrm{M}-\mathrm{T}$ ) were performed in a Quantum Design MPMS XL-7 SQUID. Particles were also examined by using a Field Emission Scanning Electron Microscope (SEM) (Carl Zeiss Ultra Plus, Germany). In this case, samples were mounted on Carbon coated copper grids (carbon films on $3 \mathrm{~mm} 400$ mesh grids, Agar Scientific) and placed in a desiccator in order to evaporate water. Finally, the grids were adhered with a double-sided adhesive tape onto metal stubs for SEM visualization. 
Thermogravimetric measurements of PLGA-Mag, PLGA-H and unprocessed PLGA (PLGA-R) were performed in duplicate on a Shimadzu TGA 50 instrument, operating in dynamic mode under flowing nitrogen $\left(50 \mathrm{~mL} \cdot \mathrm{min}^{-1}\right)$ atmosphere at heating rates of 2.5, 5, 10 and $20^{\circ} \mathrm{C} \cdot \mathrm{min}^{-1}$. Samples of $6 \mathrm{mg}$ and platinum pans were used. The TG curves obtained at different heating rates provided data for apparent activation energy computation through the Vyazovkin method ${ }^{24}$ as summarized below.

\subsubsection{Kinetic procedure}

For the thermal decomposition of the solid, it was assumed that the reaction rate can be described as

$\frac{d \alpha}{d t}=k_{0} e^{-E_{a} / R T} f(\alpha)$

in which $\mathrm{d} \alpha / \mathrm{d} t$ is the reaction rate, $\mathrm{E}_{\alpha}$ the activation energy as function of the degree of conversion $(\alpha), f(\alpha)$ a function dependent on the reaction model, $k_{0}$ the rate constant at infinite temperature, $T$ the temperature and $R$ is the gas constant.

Under non-isothermal conditions in which a sample is heated at a constant rate, the explicit temporal dependence in Equation 1 is eliminated through the trivial transformation:

$\frac{d \alpha}{d T}=\frac{1}{\beta} k(T) f(\alpha)$

$\beta$ is the constant heating rate, $\beta=\mathrm{d} T / \mathrm{d} t$ and $k(T)=k_{0} e^{-\mathrm{E}_{\mathrm{a}} / \mathrm{RT}}$. Reordering Equation 2 it can be written as

$\frac{1}{f(\alpha)} d \alpha=\frac{k_{0}}{\beta} e^{-E_{a} / R T} d T$

Integrating Equation 3 between the limits $\alpha=0$ and $\alpha=\alpha$ and the corresponding temperatures $T=T_{0}$ and $T=T$ :

$g(\alpha)=\frac{k_{0}}{\beta} \int_{T_{0}}^{T} e^{-E_{a} / R T} d T$

If $E_{\mathrm{a}} / 2 R T » 1$, Equation 4 can be rounded to

$g(\alpha) \approx \frac{k_{0}}{\beta} \frac{R}{E} T^{2} e^{-E_{a} / R T}$

Arranging Equation 5 and taking ln, we obtain

$\ln \frac{\beta}{T_{\alpha}^{2}}=\ln \left[\frac{R k_{0}}{E_{a} g(\alpha)}\right]-\frac{E_{a}}{R} \frac{1}{T_{a}}$

Equation 6 can be used to calculate the associated activation energy $E_{\alpha}$ for every conversion if at least three dynamic measurements with different heating rates are available. To use the applied kinetics (simulation, conversion plot, isoconversion plot), this new formulation requires no knowledge of the reaction model $(f(\alpha)$ or $g(\alpha))$. With these new kinetics, selection a priori of the model with all its associated errors is no longer necessary. This leads to improved results as experience has shown that the known models correctly mirror reality only in isolated cases ${ }^{25}$.

\section{Results and Discussion}

PLGA composite nanoparticles and hollow PLGA nanospheres size, polidispersity and zeta-potential data were shown in Table 1 . The hydrodynamic diameters of the samples have values similar to those already described for PLGA nanospheres obtained by emulsion method ${ }^{26}$ and polydispersity index (which indicates the size distribution of the nanoparticles, with values lower than 0.3 normally considered satisfactory). All the parameters were slightly modified after freeze-drying but without any significant difference (data not shown); with respect to PLGA-H, maghemite entrapment did not alter them in a significant manner. Figure 1 shows the morphological characterization of nanospheres by SEM. Mag-loaded PLGA nanospheres were found to be spherical with an average size of about $200 \mathrm{~nm}$; similar to the size determined by photon correlation spectroscopy. The maghemite nanoparticles encapsulated in nanospheres appeared to be well dispersed inside the PLGA nanospheres.

Figure 2 shows TG and Figure 3 shows DTG curves for PLGA-R, PLGA-H and PLGA-Mag. PLGA-R presents only

Table 1. Hydrodynamic diameter, polydispersity and zeta surface potential of PLGA-Mag and PLGA-H samples.

\begin{tabular}{llcc}
\hline Sample & $\begin{array}{c}\text { Hydrodynamic } \\
\text { diameter }(\mathbf{n m})\end{array}$ & $\begin{array}{c}\text { Polydispersity } \\
\text { index }\end{array}$ & $\begin{array}{c}\text { Zeta surface } \\
\text { potential }(\mathbf{m V})\end{array}$ \\
\hline PLGA-Mag & $201.7 \pm 0.8083$ & $0.070 \pm 0.012$ & $-4.34 \pm 0.13$ \\
PLGA-H & $248.1 \pm 8.556$ & $0.247 \pm 0.042$ & $-4.91 \pm 0.21$ \\
\hline
\end{tabular}

For average diameter measurements the error indicates the width of the distribution and for the PDI and zeta potential measurements, the error indicates the standard deviation calculated from three measurements.

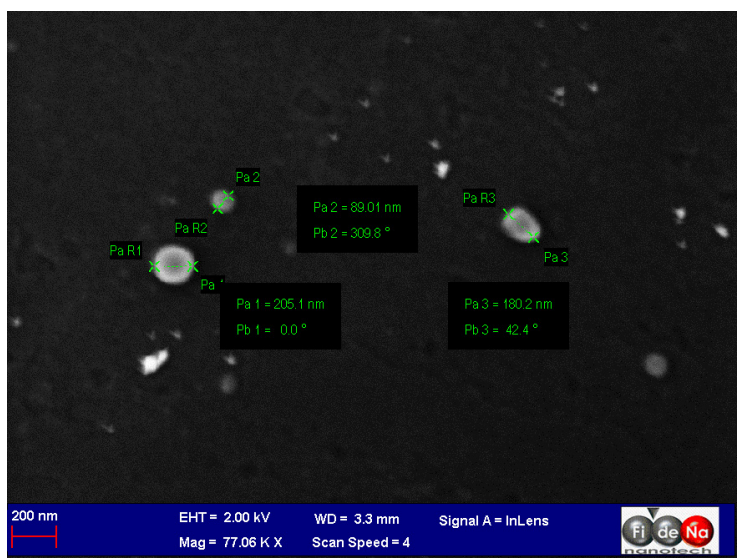

Figure 1. SEM micrograph of PLGA-Mag nanospheres.

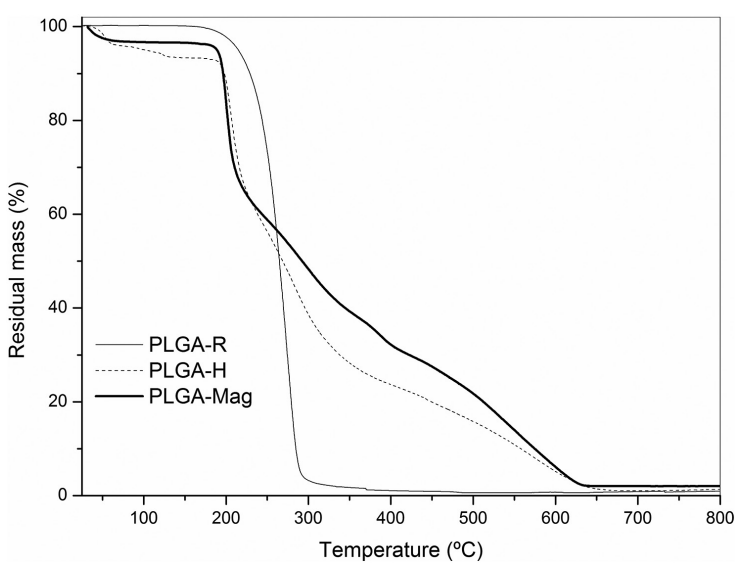

Figure 2. TG curves for PLGA-R, PLGA-H and PLGA-Mag. $\mathrm{N}_{2}$ flow rate $50.00 \mathrm{~mL} \cdot \mathrm{min}^{-1}$, heating rate of $2.5^{\circ} \mathrm{C} . \mathrm{min}^{-1}$. 
one step of weight loss between $170{ }^{\circ} \mathrm{C}$ and $370{ }^{\circ} \mathrm{C}$ and $\mathrm{T}_{\max }$ (maximum rate of decomposition temperature) near to $275^{\circ} \mathrm{C}$. This behavior is in agreement with the literature ${ }^{27,28}$.

The degradation products of PLGA are similar to those of the neat poly(lactide) (PLA) and poly(glycolide) (PGA) polymers. It has been reported ${ }^{28,29}$ that this kind of polyesters exhibits a degradation mechanism that could involve a random chain scission at the beginning of the decomposition and specific chain scission at the end. At lower temperatures, the main degradation mechanism for neat PGA and PLA involves a nonradical, backbiting ester interchange reaction involving the $\mathrm{OH}$ chain ends, leading mostly to cyclic oligomers rather than linear, with also monomer, acetaldehyde (for PLA), methyl glycolate (for PGA), and carbon dioxide, the latter obtained by decarboxylation of terminal carboxyl groups in the chains. As the temperature is raised, the release of carbon monoxide, methylketene (in the case of PLA), ketene and formaldehyde (for PGA) is produced as a consequence of a radical chain scission mechanism. No weight change was observed near to $500{ }^{\circ} \mathrm{C}$ for PLGA-R. On the other hand, PLGA-H and PLGA-Mag present two mainly steps of thermal degradation: the first step, with maximum rate of decomposition at the temperature of $205{ }^{\circ} \mathrm{C}$, and the second step, showed by a broad peak in DTG curves near to $280{ }^{\circ} \mathrm{C}$. This first step is referred to thermal degradation of sucrose, with $40 \%$ of weight loss. Before this step, only overlapped peaks occur, indicating a number of parallel and/or consecutive reactions. This behavior is related to the thermal degradation of PLGA. After $635^{\circ} \mathrm{C}$, PLGA-H shows $100 \%$ of weight loss, whereas PLGA-Mag maintains $2 \%$ of residual mass, related to entrapped maghemite. Iron oxides such as maghemite are thermally stable at temperatures up to $800^{\circ} \mathrm{C}^{[30]}$. The present results indicated that the decomposition temperature of PLGA-R is higher than that of both PLGA-H nanospheres and PLGA-Mag nanospheres. This can be attributed to the high surface area of the nanospheres and the presence of iron oxide nanoparticles that could increase the thermal conductivity of the composites ${ }^{31}$, as seen in Figure 2.

The data of $\mathrm{T}_{\text {on }}$ (decomposition onset temperature) and $\mathrm{T}_{\max }$ for the four studied rates of thermal degradation are shown in Table 2. Similar values of $\mathrm{T}_{\text {on }}$ and $\mathrm{T}_{\max }$ were reported by Palacios et al. ${ }^{28}$. As the heating rate increased there was a lateral shift towards higher temperatures for $\mathrm{T}_{\text {on }}$ and $\mathrm{T}_{\max }$ for all samples. This behavior was previously described for other materials in the literature ${ }^{32}$.

The apparent activation energy (E $\alpha$ ) of PLGA-R, PLGA-H and PLGA-Mag thermal degradation reactions under inert atmosphere was computed by the Vyazovkin isoconversional method (results in Figure 4).

In the beginning of thermal degradation (percent decomposition below 5\%), there is a variation in $\mathrm{E}_{\alpha}$ values, which are attributed to low energy processes such as the elimination of low molar weight compounds $\left(\mathrm{CO}_{2}, \mathrm{H}_{2} \mathrm{O}\right.$, etc. $)$. PLGA-R presents negative value of $-50 \pm 4.5 \mathrm{~kJ} . \mathrm{mol}^{-1}$ for activation energy below $35 \%$ of decomposition, indicating that the reaction is getting slower as the temperature is increased, whereas PLGA-Mag has activation energy of $114 \pm 9.1 \mathrm{~kJ}^{\mathrm{mol}}{ }^{-1}$ for the same range of decomposition. For PLGA-H, there is not a range of constant energy activation throughout the entire process of thermal degradation. Previous studies presented activation energy of $115 \mathrm{~kJ} . \mathrm{mol}^{-1}$ for bulk PLGA 50:50 ${ }^{[18]}, 116 \mathrm{~kJ} . \mathrm{mol}^{-1}$ for dexamethasone loaded PLGA microspheres ${ }^{33}$ indicating that the activation energy value found for PLGA-Mag is close to that demonstrated in these studies. In a general way, both PLGA-H and PLGA-Mag show higher values of activation energy than those of PLGA-R.

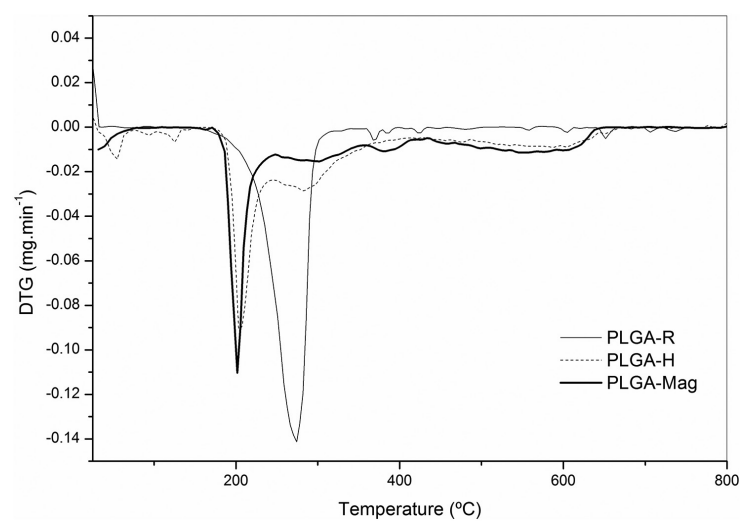

Figure 3. DTG curves for PLGA-R, PLGA-H and PLGA-Mag. $\mathrm{N}_{2}$ flow rate $50.00 \mathrm{~mL} \cdot \mathrm{min}^{-1}$, heating rate of $2.5^{\circ} \mathrm{C} \cdot \mathrm{min}^{-1}$.

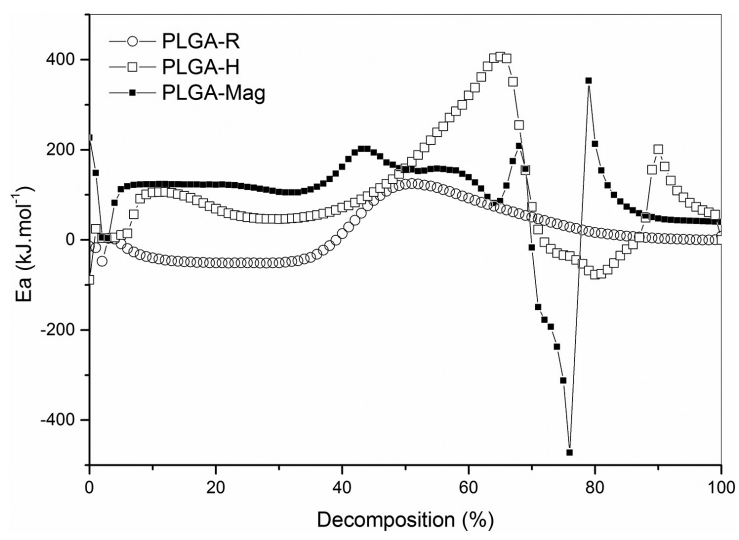

Figure 4. Variation of activation energy versus decomposition rate obtained by Vyazovkin method.

Table 2. Data of $\mathrm{T}_{\text {on }}$ and $\mathrm{T}_{\max }$ for PLGA-R, PLGA-H and PLGA-Mag at the four heating rates used on Vyazovkin $\operatorname{method}\left(\mathrm{T}_{\text {on }}\right.$ and $\mathrm{T}_{\max }$ in $\left.{ }^{\circ} \mathrm{C}\right)$.

\begin{tabular}{|c|c|c|c|c|c|c|c|c|}
\hline & \multicolumn{2}{|c|}{$2.5^{\circ} \mathrm{C} . \mathrm{min}^{-1}$} & \multicolumn{2}{|c|}{$5^{\circ} \mathrm{C} \cdot \mathrm{min}^{-1}$} & \multicolumn{2}{|c|}{$10^{\circ} \mathrm{C} \cdot \mathrm{min}^{-1}$} & \multicolumn{2}{|c|}{$20^{\circ} \mathrm{C} \cdot \mathrm{min}^{-1}$} \\
\hline & $\mathbf{T}_{\text {on }}$ & $\mathbf{T}_{\max }$ & $\mathbf{T}_{\text {on }}$ & $\mathbf{T}_{\max }$ & $\mathbf{T}_{\text {on }}$ & $\mathbf{T}_{\max }$ & $\mathbf{T}_{\mathrm{on}}$ & $\mathbf{T}_{\max }$ \\
\hline PLGA-R & 220 & 275 & 239 & 296 & 242 & 310 & 258 & 330 \\
\hline PLGA-H & 185 & 205 & 190 & 218 & 213 & 227 & 226 & 242 \\
\hline PLGA-Mag & 191 & 201 & 197 & 210 & 212 & 220 & 214 & 230 \\
\hline
\end{tabular}




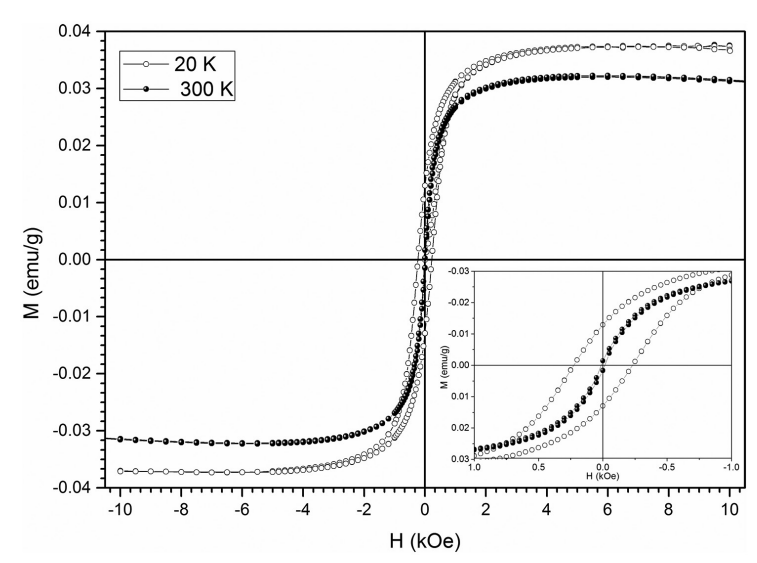

Figure 5. The magnetic property of the superparamagnetic PLGA-Mag nanospheres showing magnetization-applied magnetic field (M-H) magnetization curve.

This behavior is due to the nanoparticles formation during the emulsion process, leading to higher thermal stability. Furthermore, for PLGA-Mag, activation energy is higher than that of PLGA-H, indicating that entrapped maghemite contributes to thermal stability. In addition, studies show that the presence of inorganic material in PLGA polymer causes an increase in the activation energy of the composite, as observed in this study ${ }^{28}$.

The magnetic property of PLGA-Mag was determined by $\mathrm{M}-\mathrm{H}$ hysteresis loop behavior at 20 and $300 \mathrm{~K}$ by cycling the field between -10 and $10 \mathrm{kOe}$. Results from these studies showed that the PLGA-Mag exhibited typical superparamagnetic properties, with a saturation magnetization of $0.37 \mathrm{emu}^{-1} \mathrm{~g}^{-1}$, because of the negligible values of remanence and coercivity in the $\mathrm{M}-\mathrm{H}$ curve (Figure 5). Moreover, the superparamagnetic behavior of PLGA-Mag was confirmed from the SQUID measurement by recording field-cooled (FC) and zero-field-cooled (ZFC) magnetization under an applied field of $2 \mathrm{kOe}$ in a temperature range between 5 and $300 \mathrm{~K}$ (Figure 6). The maximum value of magnetization was obtained at blocking temperature $\left(\mathrm{T}_{\mathrm{B}}\right)$, at which the iron oxide spins were able to rotate. Beyond $\mathrm{T}_{\mathrm{B}}$, the ZFC magnetization curve nearly overlapped with the FC curve, indicating superparamagnetic behavior. The $T_{\mathrm{B}}$ was determined to be $71 \mathrm{~K}$. Notably, the blocking temperature was corroborated by the values found in the literature for superparamagnetic iron oxide nanoparticles ${ }^{34,35}$. Such

\section{References}

1. Dias AMGC, Hussain A, Marcos AS and Roque ACA. A biotechnological perspective on the application of iron oxide magnetic colloids modified with polysaccharides. Biotechnology Advances. 2011; 29(1):142-155. http://dx.doi.org/10.1016/j. biotechadv.2010.10.003. PMid:20959138.

2. Jin R, Lin B, Li D and Ai H. Superparamagnetic iron oxide nanoparticles for MR imaging and therapy: design considerations and clinical applications. Current Opinion in Pharmacology. 2014; 18:18-27. http://dx.doi.org/10.1016/j.coph.2014.08.002. PMid:25173782.

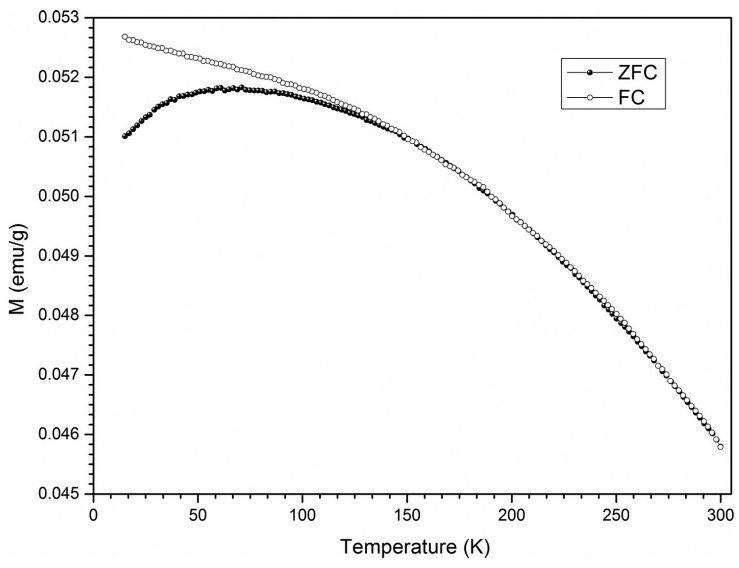

Figure 6. Superconducting quantum unit interference device (SQUID) measurement of Mag-PLGA recorded at $2 \mathrm{kOe}$ showing divergence of magnetization curves corresponding to zero field cooled (ZFC, shown in black) and field cooled (FC, shown in white) plots, indicating superparamagnetism.

superparamagnetic property has demonstrated to be critical to the successful application of magnetic nanospheres in areas such as $\mathrm{T}_{2}$-weighted magnetic resonance imaging, drug delivery and magneto-hyperthermia ${ }^{36}$.

\section{Conclusion}

Thermogravimetry is an important method for determination of materials thermal properties, allowing the measurement of thermal stability during the variation of physical/chemical properties. It can be concluded that although unprocessed PLGA (PLGA-R) undergoes thermal degradation at higher temperatures than processed materials (PLGA-H and PLGA-Mag), the latter present higher thermal stability, with higher values of activation energy measured by Vyazovkin method. Maghemite presence increases the $\mathrm{E}_{\alpha}$ of PLGA nanospheres and allows superparamagnetic behavior at room temperature, showing that this magnetic material is a good choice for the production of magnetic PLGA nanocomposites with increased thermal stability.

\section{Acknowledgements}

The authors thank Capes - DGU 184-09 and MCI Spain - PHB 2008-0044-PC for their financial support.

3. Silva MF, Oliveira LAS, Ciciliati MA, Silva LT, Pereira BS, Hechenleitner AAW, et al. Nanometric particle size and phase controlled synthesis and characterization of $\gamma-\mathrm{Fe}_{2} \mathrm{O}_{3}$ or $(\alpha+\gamma)-\mathrm{Fe}_{2} \mathrm{O}_{3}$ by a modified sol-gel method. Journal of Applied Physics. 2013; 114(10):104311-104317. http://dx.doi.org/10.1063/1.4821253.

4. Silva MF, Hechenleitner AAW, Oliveira DM, Agüeros M, Peñalva $\mathrm{R}$, Irache JM, et al. Optimization of maghemite-loaded PLGA nanospheres for biomedical applications. European Journal of Pharmaceutical Sciences. 2013; 49(3):343-351. http://dx.doi. org/10.1016/j.ejps.2013.04.006. PMid:23602998.

5. Zhang Y, Sun C, Kohler N and Zhang M. Self-assembled coatings on individual monodisperse magnetite nanoparticles for efficient 
intracellular uptake. Biomedical Microdevices. 2004; 6(1):3340. http://dx.doi.org/10.1023/B:BMMD.0000013363.77466.63. PMid:15307442.

6. Lu A-H, Salabas EL and Schüth F. Magnetic nanoparticles: synthesis, protection, functionalization, and application. Angewandte Chemie International Edition. 2007; 46(8):1222-1244. http:// dx.doi.org/10.1002/anie.200602866. PMid:17278160.

7. Tian H, Tang Z, Zhuang X, Chen X and Jing X. Biodegradable synthetic polymers: preparation, functionalization and biomedical application. Progress in Polymer Science. 2012; 37(2):237-280. http://dx.doi.org/10.1016/j.progpolymsci.2011.06.004.

8. Mahmoudi M, Sant S, Wang B, Laurent S and Sen T. Superparamagnetic iron oxide nanoparticles (SPIONs): development, surface modification and applications in chemotherapy. Advanced Drug Delivery Reviews. 2011; 63(1-2):24-46. http://dx.doi. org/10.1016/j.addr.2010.05.006. PMid:20685224.

9. Philippova O, Barabanova A, Molchanov V and Khokhlov A. Magnetic polymer beads: recent trends and developments in synthetic design and applications. European Polymer Journal. 2011; 47(4):542-559. http://dx.doi.org/10.1016/j. eurpolymj.2010.11.006.

10. Furlan M, Kluge J, Mazzotti M and Lattuada M. Preparation of biocompatible magnetite-PLGA composite nanoparticles using supercritical fluid extraction of emulsions. The Journal of Supercritical Fluids. 2010; 54(3):348-356. http://dx.doi. org/10.1016/j.supflu.2010.05.010.

11. Tang X, Liang Y, Feng X, Zhang R, Jin X and Sun L. Codelivery of docetaxel and Poloxamer 235 by PLGA-TPGS nanoparticles for breast cancer treatment. Materials Science and Engineering C. 2015; 49:348-355. http://dx.doi.org/10.1016/j. msec.2015.01.033. PMid:25686959.

12. Schleich N, Sibret P, Danhier P, Ucakar B, Laurent S, Muller $\mathrm{RN}$, et al. Dual anticancer drug/superparamagnetic iron oxide-loaded PLGA-based nanoparticles for cancer therapy and magnetic resonance imaging. International Journal of Pharmaceutics. 2013; 447(1-2):94-101. http://dx.doi.org/10.1016/j. ijpharm.2013.02.042. PMid:23485340.

13. Li Y-J, Dong M, Kong F-M and Zhou J-P. Folate-decorated anticancer drug and magnetic nanoparticles encapsulated polymeric carrier for liver cancer therapeutics. International Journal of Pharmaceutics. 2015; 489(1-2):83-90. http://dx.doi. org/10.1016/j.ijpharm.2015.04.028. PMid:25888801.

14. Nogueira DR, Scheeren L, Macedo L, Marcolino AI, Pilar Vinardell M, Mitjans M, et al. Inclusion of a pH-responsive amino acid-based amphiphile in methotrexate-loaded chitosan nanoparticles as a delivery strategy in cancer therapy. Amino Acids. 2015. Epub ahead of print. PMid:26306845.

15. Farooqi AA, Fayyaz S, Shatynska-Mytsyk I, Javed Z, Jabeen $\mathrm{S}$, Yaylim I, et al. Is miR-34a a well equipped swordsman to conquer temple of molecular oncology? Chemical Biology \& Drug Design. 2015. Epub ahead of print. http://dx.doi. org/10.1111/cbdd.12634. PMid:26259537.

16. Farooqi AA, Rehman ZU and Muntane J. Antisense therapeutics in oncology: current status. OncoTargets and Therapy. 2014; 7:2035-2042. http://dx.doi.org/10.2147/OTT.S49652. PMid:25395862.

17. Farooqi AA and De Rosa G. TRAIL and microRNAs in the treatment of prostate cancer: therapeutic potential and role of nanotechnology. Applied Microbiology and Biotechnology. 2013; 97(20):8849-8857. http://dx.doi.org/10.1007/s00253013-5227-9. PMid:24037407.

18. Agrawal C, Huang D, Schmitz J and Athanasiou K. Elevated temperature degradation of a 50: 50 copolymer of PLA-PGA.
Tissue Engineering. 1997; 3(4):345-352. http://dx.doi.org/10.1089/ ten.1997.3.345.

19. Tudorachi N, Chiriac AP, Neamtu I, Nistor MT and Lisa G. Synthesis and thermal analysis of a magnetic composite by thermogravimetry coupled to fourier transform infrared spectroscopy and mass spectrometry. Industrial \& Engineering Chemistry Research. 2012; 51(1):335-344. http://dx.doi. org/10.1021/ie2020203.

20. Islam S. Lipophilic and hydrophilic drug loaded PLA/PLGA in situ implants: studies on thermal behavior of drug \& polymer and observation of parameters influencing drug burst release with corresponding effects on loading efficiency \& morphology of implants. International Journal of Pharmacy and Pharmaceutical Sciences. 2011; 3:181-188.

21. Wan F, Bohr A, Maltesen M, Bjerregaard S, Foged C, Rantanen $\mathrm{J}$, et al. Critical solvent properties affecting the particle formation process and characteristics of celecoxib-loaded plga microparticles via spray-drying. Pharmaceutical Research. 2013;30(4):1065-1076. http://dx.doi.org/10.1007/s11095-0120943-x. PMid:23263784.

22. De S and Robinson D. Particle size and temperature effect on the physical stability of PLGA nanospheres and microspheres containing Bodipy. Journal of the American Association of Pharmaceutical Scientists. 2004; 5(4):18-24. http://dx.doi. org/10.1208/pt050453. PMid:15760050.

23. Vyazovkin S, Burnham AK, Criado JM, Pérez-Maqueda LA, Popescu C and Sbirrazzuoli N. ICTAC Kinetics Committee recommendations for performing kinetic computations on thermal analysis data. Thermochimica Acta. 2011; 520(1-2):119. http://dx.doi.org/10.1016/j.tca.2011.03.034.

24. Vyazovkin S and Wight CA. Model-free and model-fitting approaches to kinetic analysis of isothermal and nonisothermal data. Thermochimica Acta. 1999; 340-341:53-68. http://dx.doi. org/10.1016/S0040-6031(99)00253-1.

25. Fernandes DM, Hechenleitner AAW and Pineda EAG. Kinetic study of the thermal decomposition of poly(vinyl alcohol)/ kraft lignin derivative blends. Thermochimica Acta. 2006; 441(1):101-109. http://dx.doi.org/10.1016/j.tca.2005.11.006.

26. Okassa LN, Marchais H, Douziech-Eyrolles L, Hervé K, Cohen-Jonathan S, Munnier E, et al. Optimization of iron oxide nanoparticles encapsulation within poly(D,L-lactideco-glycolide) sub-micron particles. European Journal of Pharmaceutics and Biopharmaceutics. 2007; 67(1):31-38. http://dx.doi.org/10.1016/j.ejpb.2006.12.020. PMid:17289360.

27. Erbetta CDC, Viegas CCB, Freitas RFS and Sousa RG. Síntese e caracterização térmica e química do copolímero Poli (D, L-lactídeo-co-glicolídeo). Polímeros. 2011; 21(5):376-382. http://dx.doi.org/10.1590/S0104-14282011005000063.

28. Palacios J, Albano C, González G, Castillo RV, Karam A and Covis M. Characterization and thermal degradation of poly $(\mathrm{d}, 1-$ lactide-co-glycolide) composites with nanofillers. Polymer Engineering and Science. 2013; 53(7):1414-1429. http://dx.doi. org/10.1002/pen.23396.

29. Sivalingam $G$ and Madras G. Thermal degradation of binary physical mixtures and copolymers of poly( $\varepsilon$-caprolactone), poly(d, l-lactide), poly(glycolide). Polymer Degradation \& Stability. 2004; 84(3):393-398. http://dx.doi.org/10.1016/j. polymdegradstab.2003.12.008.

30. Cornell RM and Schwertmann U. The iron oxides: structures, properties, reactions, occurrences and uses. Weinheim: Wiley$\mathrm{VCH} ; 2003$.

31. Khalil KA, Fouad H, Elsarnagawy T and Almajhdi FN. Preparation and characterization of electrospun PLGA/silver 
composite nanofibers for biomedical applications. International Journal of Electrochemical Science. 2013; 8:3483-3493.

32. Aouad A, Bilali L, Benchanâa M and Mokhlisse A. Kinetic aspect of thermal decomposition of natural phosphate and its kerogen. Influence of heating rate and mineral matter. Journal of Thermal Analysis and Calorimetry. 2002; 67(3):733-743. http://dx.doi.org/10.1023/A:1014329526885.

33. Shen $J$ and Burgess DJ. Accelerated in vitro release testing of implantable PLGA microsphere/PVA hydrogel composite coatings. International Journal of Pharmaceutics. 2012; 422(12):341-348. http://dx.doi.org/10.1016/j.ijpharm.2011.10.020. PMid:22016033.

34. Hyeon T, Lee SS, Park J, Chung Y and Na HB. Synthesis of highly crystalline and monodisperse maghemite nanocrystallites without a size-selection process. Journal of the American Chemical Society. 2001; 123(51):12798-12801. http://dx.doi. org/10.1021/ja016812s. PMid:11749537.

35. Dutta RK and Sahu S. Development of oxaliplatin encapsulated in magnetic nanocarriers of pectin as a potential targeted drug delivery for cancer therapy. Results in Pharma Sciences. 2012; 2:38-45. http://dx.doi.org/10.1016/j.rinphs.2012.05.001. PMid:25755993.

36. Sun Y, Zheng Y, Ran H, Zhou Y, Shen H, Chen Y, et al. Superparamagnetic PLGA-iron oxide microcapsules for dualmodality US/MR imaging and high intensity focused US breast cancer ablation. Biomaterials. 2012; 33(24):5854-5864. http:// dx.doi.org/10.1016/j.biomaterials.2012.04.062. PMid:22617321. 